\title{
Collective Chord Behavior in Large Flexible Diaphragms
}

\author{
J. W. Lawson ${ }^{1}$ and C. N. Yarber ${ }^{2}$
}

\begin{abstract}
The seismic behavior of large low-rise buildings with rigid walls and flexible diaphragms will be dominated more by the diaphragm's seismic response than by the very stiff vertical walls. For practitioners, estimating the stiffness of large flexible diaphragms is important for computing building setbacks from property lines and adjacent structures as well as evaluating structural integrity under seismic loads. In addition, researchers attempting to accurately model a building's dynamic behavior need to assemble an accurate diaphragm stiffness prediction. The traditional diaphragm chord model consists of a single continuous line of axial resistance at the diaphragm boundaries; however, as this paper will demonstrate a collective series of structural members distributed across the diaphragm will function intentionally or unintentionally as a collective chord, adding significant flexural stiffness and reducing chord forces. In seismically active areas, masonry and concrete wall anchorage forces utilize code-mandated continuous cross-ties within the diaphragm, and often these cross-ties are sufficiently strong and stiff to unintentionally develop collective chord behavior whether in steel or in wood diaphragm systems. While neglecting this embedded collective chord behavior results in conservative chord and diaphragm drift designs, researchers or practitioners trying to predict seismic response of these buildings will potentially underestimate the true seismic response.
\end{abstract}

\section{INTRODUCTION}

The use of flexible roof diaphragms in low-rise buildings is very common in the United States, and consists typically of either untopped steel decking or wood structural panels across a low-slope structural roof system. Design of these diaphragms simulates a simple beam model where the decking or wood structural panels are assumed to provide the beam's shear resistance (web action), and designated chords are assumed to provide the beam's bending resistance (flange action). Because of the dimensions of this deep beam, both shear and flexure criteria need to be checked during the design process, both in terms of strength and stiffness.

The need to design for both bending and shear forces is provided by ASCE 7-10 $\$ 12.10 .1$. Additionally, the computation of diaphragm deflection is used by practitioners to determine building setbacks from property lines and adjacent 
buildings as well as investigate deformation compatibility and structural integrity within the building per ASCE 7-10 §12.12. Additionally, diaphragm deflection can be used to investigate building stability due to $P \Delta$ effects using ASCE $7-10 § 12.8 .7$ (SEAOC 2012).

These roof systems are very common in big-box retail, distribution warehouses, and commercial/industrial occupancies; and are often used in conjunction with concrete and masonry wall systems. Typically, a traditional chord model assumes a perimeter continuous tie element at the diaphragm extreme. The design provisions also require these heavy wall buildings to be anchored well into the roof diaphragm structure to prevent wall-to-roof connection failures that have been common during past earthquakes (SEAONC 2001, SEAOC 2008). These seismic design forces and detailing requirements have increased significantly over time causing diaphragms to become much more interconnected and robust to resist seismic wall anchorage forces.

This internal interconnection of beams and girders, called continuity ties in ASCE 7, results in a structure that has different flexural behavior from a traditional diaphragm chord model, and can have a substantial effect on the design and actual response of the structure. Wall anchorage forces are required to be distributed across the diaphragm depth with continuous cross-ties in Seismic Design Categories $\mathrm{C}$ and higher (ASCE 7-10 $\$ 12.11 .2 .2 .1$ ). These continuous cross-ties involve numerous parallel framing members tied together to resist wall anchorage tension forces during seismic events (Figures $1 \& 2$ ). The requirement for continuous cross-ties dates back to the 1973 Uniform Building Code provisions introduced after observing the wall anchorage failures from the 1971 San Fernando earthquake (SEAOC 2008) and is implemented in large flat flexible diaphragms in high seismic regions. Designed primarily for the wall anchorage system, these continuous cross-ties can unintentionally also act as chord elements collectively. This is especially true in buildings with large diaphragms where numerous repetitive interconnected beams or joists occur in parallel as well as several or more parallel girder lines.

Other building code requirements that can potentially create unintentional collective chord elements are the ASCE 7-10 provisions for structural integrity $(\S 1.4)$ and minimum structural interconnection $(\$ 12.1 .3)$. Similar to continuous cross-ties, these provisions require the building and diaphragm to be interconnected for robustness and distribution of lateral forces. This interconnection of elements has a tendency to add additional collective chord elements.

\section{TRADITIONAL CHORD BEHAVIOR ASSUMPTION}

The current state of design practice is to design flexible diaphragms using a simply beam analogy. Chords are critical to carry the tension forces developed by the flexural bending moments in the diaphragm under lateral load. Traditionally, diaphragm chords are thought of as Tension/Compression force couples at the diaphragm extreme edges. The following model and equations illustrate a traditional chord approach for a flexible diaphragm. 


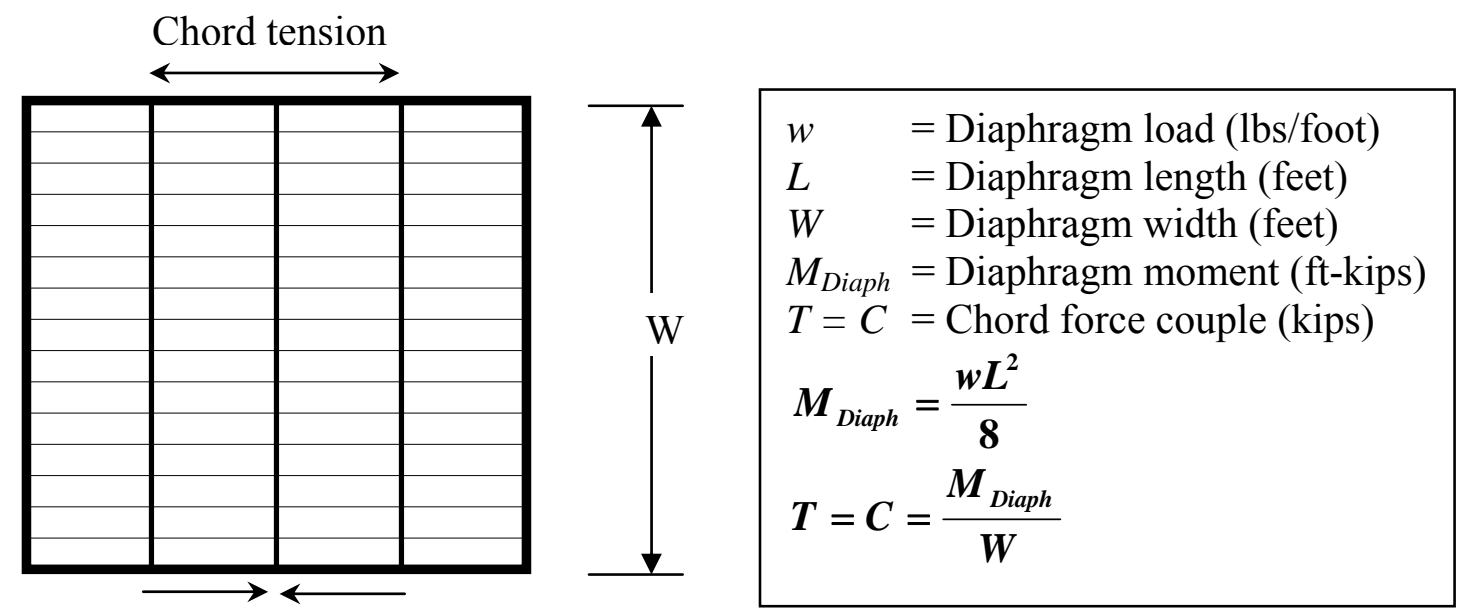

Chord compression

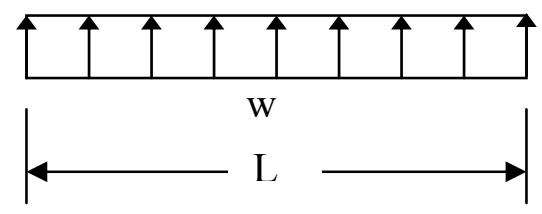

Figure 1. Plan View of Traditional Chord Forces.

Besides resisting bending forces, chords also resist bending deformation of the diaphragm. More specifically, the deflection of a flexible diaphragm is composed of bending component $\Delta_{f}$ associated with the chords (or flanges), and a shear component $\Delta_{w}$ associated with the deck (or web).

$\Delta_{\text {diaph }}=\Delta_{f}+\Delta_{w}$

Reference design standards for both wood and steel deck diaphragms recognize this two component approach to computing deflections (AF\&PA 2009, SDI 2004). The chord dependent bending deflection $\Delta_{f}$ may be computed by the following equation from SDPWS-2008 Equation 4.2-1 (AF\&PA 2009) when the traditional single chord model is assumed.

$$
\Delta_{f}=\frac{5 v L^{3}}{8 E A W}
$$

where:

$$
\begin{array}{ll}
E & =\text { Modulus of elasticity of chords }(\mathrm{psi}) \\
A & =\text { Area of chord cross-section }\left(\mathrm{in}^{2}\right) \\
W & =\text { Diaphragm width }(\mathrm{ft}) \\
L & =\text { Diaphragm length }(\mathrm{ft}) \\
V & =\text { Maximum diaphragm shear in the direction under consideration (plf) } \\
\Delta_{f} & =\text { Maximum mid-span diaphragm deflection from bending (in) }
\end{array}
$$




\section{COLLECTIVE CHORD BEHAVIOR}

As mentioned earlier, the interconnection of the diaphragm members may result in intentional or unintentional collective chord behavior. The efficiency of each continuous chord element to resist bending is a function of its distance from the diaphragm's neutral axis. To analyze the forces introduced into these collective chord elements, strain compatibility is utilized instead of a simplistic tension/compression force couple. Assuming the behavior as linearly elastic, Figure 2 depicts a diaphragm plan view illustrating the force distribution.

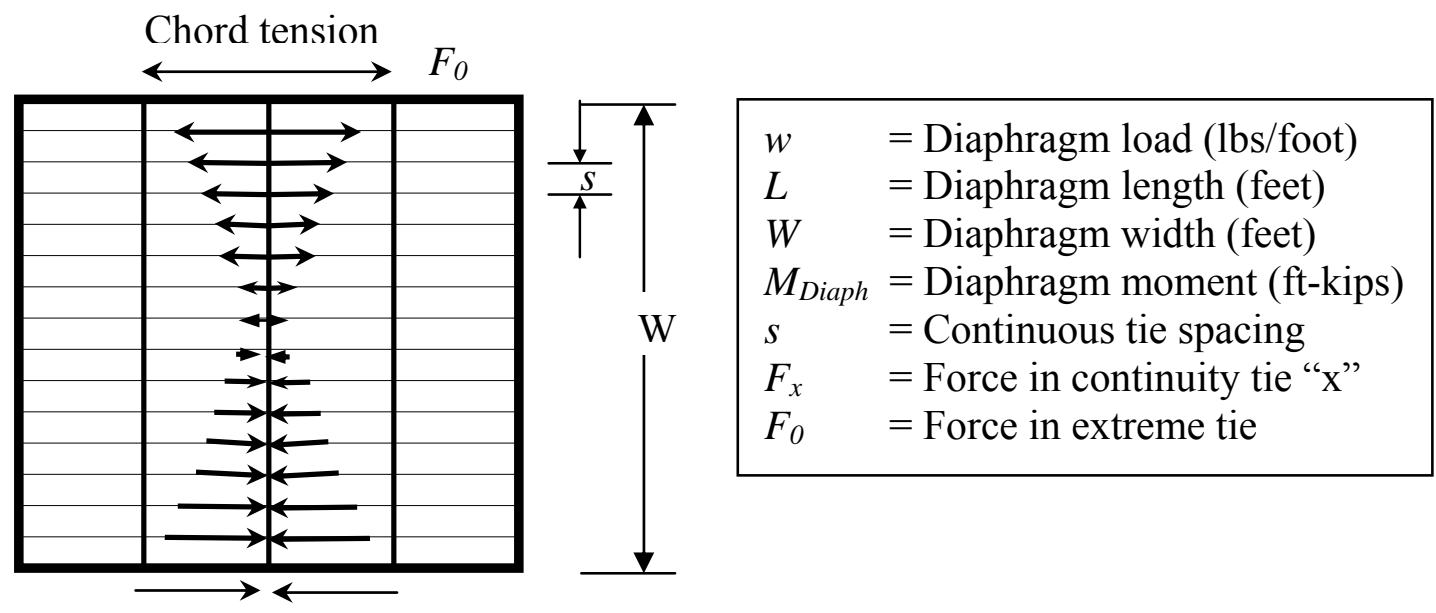

Chord compression

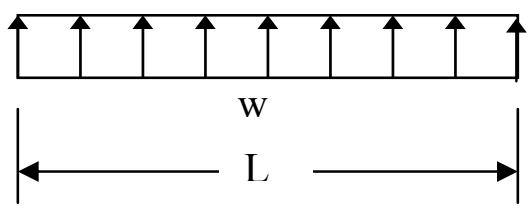

Figure 2. Collective Chord Force Distribution.

Each continuous cross-tie has a different chord force proportional to its distance from the bending neutral axis. Simple equations may be derived for the design engineer to compute the reduced forces (Lawson 2007). To simplify the equation presentation, the various continuous cross-ties forces $F_{X}$ can be expressed in terms of the extreme cross-tie's force $F_{0}$. For example, the first tie inward from the diaphragm's extreme tie has a force $F_{1}$, and for all ties the force may be expressed as $F_{X}$ :

$$
F_{1}=F_{0} \frac{W / 2-s}{W / 2} \quad F_{x}=F_{0} \frac{W / 2-s x}{W / 2}=F_{0}\left(1-\frac{2 s x}{W}\right) \quad \text { EQ. } 1
$$

Equation 1 defines the force in each chord element relative to the extreme (traditional chord) element. When $s x>W / 2$, the collective chord forces determined in Equation 1 go negative crossing the neutral axis. It is this point that the chord forces go from 
tension to compression. Figure 3 graphically illustrates the distribution and labeling of collective chord forces. Using statics, the following simple series is developed:

$$
M_{\text {Diaph }}=F_{0} W+F_{1}(W-s)+F_{2}+F_{3}(W-3 s) \ldots+F_{n}(W-n s)(W-2 s)
$$

This may be also expressed simply as a summation:

$$
M_{\text {Diaph }}=\sum_{x=0}^{n} F_{x}(W-s x) \text { where...n } \approx \frac{W}{s}
$$

EQ. 2

Substituting Equation 1 into Equation 2 and simplifying:

$$
\begin{aligned}
& M_{\text {Diaph }}=\sum_{x=0}^{n} F_{0}\left(1-\frac{2 s x}{W}\right)(W-s x) \\
& M_{\text {Diaph }}=\frac{F_{0}}{W} \sum_{x=0}^{n}\left(2 s^{2} x^{2}-3 W s x+W^{2}\right)
\end{aligned}
$$

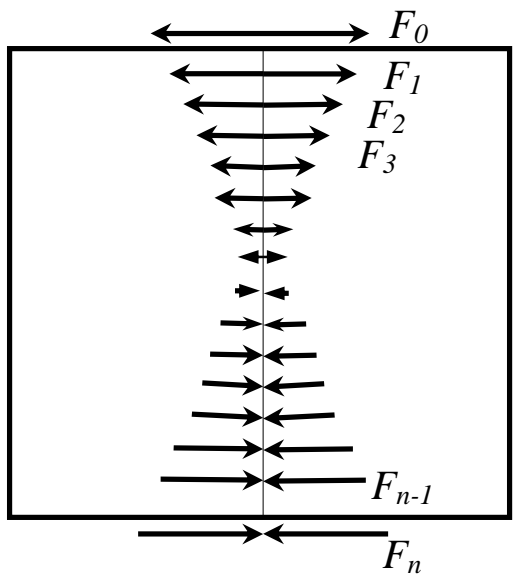

Solving for $F_{0}$ :

Figure 3. Collective Chord Forces.

$$
\boldsymbol{F}_{0}=\frac{\boldsymbol{M}_{\text {Diaph }} \boldsymbol{W}}{\sum_{x=0}^{n}\left(2 s^{2} x^{2}-3 W s x+W^{2}\right)} \quad \text { where...n } \approx \frac{W}{s}
$$

EQ. 3

The only variable in Equation 3 is $x$, and $F_{0}$ can be solved by using a simple summation in the denominator. Using some additional math, the summation in the denominator can be simplified further for a direct solution. Simplify the denominator:

$$
\begin{aligned}
& \sum_{x=0}^{n}\left(2 s^{2} x^{2}-3 W s x+W^{2}\right) \quad \text { where } \ldots n \approx \frac{W}{s} \\
= & W^{2}+2 s^{2} \sum_{x=1}^{n} x^{2}-3 W s \sum_{x=1}^{n} x+W^{2} \sum_{x=1}^{n} 1 \\
= & W^{2}+2 s^{2}\left(\frac{n(n+1)(2 n+1)}{6}\right)-3 W s\left(\frac{n(n+1)}{2}\right)+W^{2} n \\
= & \frac{2}{3} s^{2} n^{3}+s^{2} n^{2}+\frac{1}{3} s^{2} n-\frac{3}{2} W s n^{2}-\frac{3}{2} W s n+W^{2} n+W^{2}
\end{aligned}
$$

The variable $n$ represents the number of cross-ties evenly spaced across the diaphragm depth. This may also be expressed as the diaphragm depth divided by the 
cross-tie spacing $n=W / s$. Substituting $W / s$ for $n$, our denominator equation can be further simplified as follows:

$$
\begin{aligned}
& =\frac{2 s^{2} W^{3}}{3 s^{3}}+\frac{s^{2} W^{2}}{s^{2}}+\frac{s^{2} W}{3 s}-\frac{3 W s W^{2}}{2 s^{2}}-\frac{3 W s W}{2 s}+\frac{W^{2} W}{s}+W^{2} \\
& =\frac{W}{6 s}(W+s)(W+2 s)
\end{aligned}
$$

Substituting the simplified summation above into Equation 3, we can solve for $F_{0}$ :

$$
F_{0}=\frac{6 s M_{\text {Diaph }}}{(W+s)(W+2 s)}
$$

EQ. 4

Equation 4 is particularly useful in large diaphragms with high traditional chord forces, and where numerous collective chord elements are likely to exist. Often the resulting chord force developed in the repetitive members is less than the wall anchorage axial design load in the members, and thus will not govern the design.

Also, recall that a diaphragm's overall deflection has a bending contribution, and this contribution is a direct function of the chord model assumed. Beginning with the traditional deflection equation of a uniformly loaded beam, a suitable equation can be developed that incorporates a collective chord:

$$
\Delta_{f}=\frac{5 w L^{4}}{384 E I}
$$

All variables utilize pounds and inches. In order to accommodate more customary units of feet for length $\boldsymbol{L}$ and pounds per linear foot for uniform load $\boldsymbol{w}$, the bending deflection equation is modified as follows for unit consistency:

$$
\Delta_{\text {bending }}=\frac{5\left(\frac{w}{12}\right)(L \times 12)^{4}}{384 E I}=\frac{5 w L^{4}(1728)}{384 E I}=\frac{45 w L^{4}}{2 E I} \quad \text { EQ. } 5
$$

where:

$$
\begin{array}{ll}
w & =\text { Applied uniform loading (plf) } \\
L & =\text { Diaphragm length }(\mathrm{ft}) \\
E & =\text { Elastic modulus of chords (psi) } \\
I & =\text { Moment of inertia }\left(\mathrm{in}^{4}\right)
\end{array}
$$

It is desirable to have an equation in terms of the maximum diaphragm shear $\boldsymbol{v}$ (plf) instead of the applied uniform load $w$ in order that the diaphragm deflection of other non-uniformly loaded conditions can be approximated. 
$v=\frac{V}{W}=\frac{w L}{2} \frac{1}{W} \quad$ or rewritten, $\quad w=\frac{2 v W}{L}$

where $\boldsymbol{V}$ is the diaphragm shear reaction (lbs), and $\boldsymbol{W}$ is the diaphragm width ( $\mathrm{ft}$ ). Substituting into Equation 5:

$$
\Delta_{\text {bending }}=\frac{45(2 v b) L^{3}}{2 E I}=\frac{45 v b L^{3}}{E I}
$$

Using the parallel axis theorem for the moment of inertia, a new expression for the collective chord's moment of inertia can be derived. The moment of inertia of each individual chord element $\boldsymbol{I}_{\boldsymbol{X}}$ is insignificant and assumed as zero.

$$
I=\sum\left(I_{x}+A_{x} d_{x}^{2}\right)=\sum\left(A_{n} d_{x}^{2}\right)
$$

Using Figure 3 but replacing the force $F_{x}$ with the chord area $A_{x}$, the following series represents the collective chord moment of inertia, where $s$ represents the uniform spacing of the continuous chord elements.

$$
\begin{aligned}
& I=A_{0}\left(\frac{W}{2}\right)^{2}+A_{1}\left(\frac{W}{2}-s\right)^{2}+A_{2}\left(\frac{W}{2}-2 s\right)^{2}+\ldots+A_{n}\left(\frac{W}{2}-n s\right)^{2} \\
& =\sum_{x=0}^{n} A_{x}\left(\frac{W}{2}-s x\right)^{2}
\end{aligned}
$$

This can be simplified further by removing the summation operator. In addition, the chord element areas can be assumed to be all equal, or conservatively consider the smallest occurring chord element area.

$$
I=A\left(\frac{s^{2} n^{3}}{3}+\frac{s^{2} n^{2}}{2}+\frac{s^{2} n}{6}-\frac{W s n^{2}}{2}-\frac{W s n}{2}+\frac{W^{2} n}{4}+\frac{W^{2}}{4}\right) \text { where } n=\frac{W}{s} .
$$

Substituting and simplifying, the following is obtained for the moment of inertia

$$
I=\frac{A W}{12 s}(W+2 s)(W+s)
$$

This expression represents the collective chord moment of inertia. Customarily the diaphragm width $\boldsymbol{W}$ and collective chord spacings $\boldsymbol{S}$ are in feet, but the area $\boldsymbol{A}$ and moment of inertia $\boldsymbol{I}$ are in inches ${ }^{2}$ and inches ${ }^{4}$ respectfully. To maintain consistency of units Equation 7 is modified as follows:

$$
I=\frac{12 A W}{s}(W+2 s)(W+s)
$$

EQ. 8 
Substituting Equation 8 into Equation 7, a new bending deformation component for horizontal diaphragms is achieved for the collective chord model.

$$
\Delta_{f}=\frac{45 v W L^{3}}{E I}=\frac{45 v W L^{3}}{E\left(\frac{12 A W}{s}\right)(W+2 s)(W+s)}
$$

$$
\Delta_{f}=\frac{15 v L^{3} s}{4 E A(W+2 s)(W+s)}
$$

\section{IMPACT OF COLLECTIVE CHORD BEHAVIOR}

Current diaphragm design methodology by practitioners assumes a traditional chord model, where a continuous structural element is at the diaphragm extremes to resist the compression and tension forces from diaphragm bending. By ignoring the interior chord elements that may participate collectively, designers and researchers should understand the impact this may have on their work. Ignoring collective chord behavior can be a conservative design option; however, at times it may produce unconservative results for certain applications.

An inherent benefit of a collective chord system is the flexural redundancy advantage over a single isolated chord. Current ASCE 7-10 provisions (\$12.3.4) penalize buildings with non-redundant vertical lateral-force-resisting systems, such as shear walls and frames, but no such provisions currently exist for horizontal diaphragms. Researchers pondering the failure behavior of large flexible diaphragms supported by rigid walls anticipate that the structure's failure mode may occur in the diaphragm instead of the main lateral force resisting system (rigid walls). With the consideration of numerous collective chord elements, a flexural diaphragm failure is not likely to govern. Instead, a shear failure mode diaphragm becomes much more likely. Experimental research indicate that diaphragm shear failure modes seldom rupture the deck material, but instead fail the fasteners such as nails with wood systems and welds/screws/pins with steel deck systems (Tissell 2000, Rogers 2003)

When numerous collective chord elements engage as the diaphragm bends, the perimeter chord force significantly reduces from the traditional model. A large diaphragm example (480- $\mathrm{ft}$ square) investigated by one author found an $84 \%$ reduction in calculated perimeter chord force when considering collective chord behavior (Yarber 2012). Practitioners designing large diaphragms may welcome this approach to reduce chord forces to a more manageable level.

Another benefit of the collective chord model is that diaphragm deflections are less than that computed with a traditional chord model, because the bending portion of the diaphragm deflection $\Delta_{f}$ is reduced. Depending upon the diaphragm configuration and traditional chord design, $\Delta_{f}$ can be a significant contribution to the total deflection. As mentioned earlier, ASCE 7 limits diaphragm deflections for purposes of building 
setbacks and separations as well as deformation compatibility, structural integrity, and building stability.

On the other hand, the traditional chord model may produce unconservative results for practitioners and researchers conducting an analysis that utilizes the diaphragm's dynamic response as criteria in determining seismic forces within the building. The development of the diaphragm deflection Equation 4.2-1 for wood structural panels (AF\&PA 2009) neglected any bending stiffness within the web structure, and thus the stiffness will be somewhat underestimated in that regard (ATC 1981). Additionally other researchers have found evidence that computing building or diaphragm periods using dynamics, FEMA 356 (ASCE 41), and other analytical methods tend to overestimate the period when compared with instrumented building records (Harris et. al. 1998, Graf 2004) and thus underestimate the response forces. Collective chord behavior is one source of additional stiffness that is likely contributing to this disparity.

When using ASCE 31-03 to evaluate and/or ASCE 41-06 to rehabilitate an existing one-story building with a flexible diaphragm, the diaphragm period is estimated based on the computed diaphragm deflection (ASCE 31-03 \$4.2.2.1.2 and ASCE 41-06 $\S 3.3 .1 .2 .3)$ and in turn used to compute seismic response and forces. If the diaphragm stiffness is underestimated, ASCE $31 \& 41$ will underestimate the lateral force used in evaluation and rehabilitation. Under a traditional chord model, $\Delta_{f}$ often contributes a significant amount of calculated deflection to the total, potentially resulting in an underestimation of stiffness. In heavy wall buildings with numerous collective chords, it is the authors' recommendation that the bending component of diaphragm deflection $\Delta_{f}$ be assumed as zero for the purpose of computing seismic forces.

The low chord forces and high chord redundancy are likely to cause an elastic response in at least one orthogonal direction even at maximum expected force levels (Yarber 2012) and this can result in unexpected diaphragm force amplification. Research indicates that the dynamic amplification associated with flexible diaphragms is worst in the longitudinally loaded direction of buildings with large flexible diaphragms (Harris et. al. 1998). Transverse seismic resistance begins to go non-linear near maximum seismic loads, thus reducing the amplification, but because tilt-up buildings are often long and narrow, diaphragm shear design is more governed by transverse forces, resulting in conservative overstrength in the longitudinal direction. Additionally, roof framing systems typically have the more numerous transverse beams acting as cross-ties compared with the few longitudinal girder lines, causing strong collective chord behavior for the longitudinal loaded direction. This results in more elastic diaphragm behavior and thus greater force amplification in the longitudinal direction.

Another repercussion of the collective chord model is its impact on the shear distribution across the diaphragm width $W$. With bending being resisted by distributed elements across $W$, the shear stresses could theoretically be $1.5 \mathrm{~V} / \mathrm{A}$ as in a classic rectangular cross-section. This is one area of future research being planned. 


\section{SENSITIVITY TO CHORD CONNECTION BEHAVIOR}

The bending component of diaphragm deflection increases when slip occurs in the chord connections with a new component $\Delta_{\text {slip. }}$ SDPWS-2008 Equation 4.2-1 (AF\&PA 2009) contains a general-use chord connection slip component when the traditional single chord model is assumed,

$$
\Delta_{\text {slip }}=\frac{\sum\left(\Delta_{C} X\right)}{2 W}
$$

where $\Sigma\left(\Delta_{C} X\right)$ is the sum of individual chord splice slip values " $\Delta_{C}$ " on both sides of the diaphragm, each multiplied by their respective distance " $X$ " to the nearest lateral support. When considering collective chord behavior, this equation must be modified; however, today's structural chord systems usually have no slip. Steel chord systems and continuous steel cross-tie systems are typically fastened with welds or slipcritical bolts resulting in $\Delta_{C}=0$. Continuous cross-tie systems involving wood member framing typically utilized pre-manufactured tie-down anchors for connections, and any slip or slack is taken out with a finger-tight nut plus $1 / 3$ turn per the manufacturer's instructions (Simpson Strong-Tie 2013, USP 2011).

One concern to the authors was whether there was excessive flexibility or stretch within wood-to-wood tie-down (hold-down) connections commonly used in continuous cross-ties, preventing effective collective chord engagement. These types of connectors are often used for seismic retrofitting of existing panelized wood roof systems in California. An experimental testing program was conducted at Cal Poly, San Luis Obispo, measuring strength and stiffness behavior of four common connector assemblies, shown in Figure 4 (Yarber 2012). Simpson Strong-Tie connectors (MST60, HDU8-S2.5, HD7B) were fastened to 3-1/8" x 27" Douglas-fir glue-laminated (glulam) timber specimens and tested in conformance with ICC Acceptance Criteria AC155. The Simpson Strong-tie products were used due to their dominance in the seismic retrofit of these roof systems. The connectors and configurations involved nails, screws, and bolts, with a variety of single-sided and double-sided arrangements.

Based on the results of these tests, Yarber concluded that the combined glulam axial and experimentally determined connector stiffnesses are sufficient to engage collective chord behavior whether intentional or unintentional. In addition, it was determined that linearly elastic behavior is likely in the hold-down connectors when acting collectively in large buildings, even at maximum expected earthquake force levels due to the connectors' excess capacity. Thus the linear distribution of forces relative to the diaphragm's bending neutral axis is a reasonable assumption. Continuous cross-tie connectors installed with loose nuts or slack rods were not a part of this research and could affect whether the ties act as a chord collectively. 


\section{Series Comparison of Force vs Deflection}

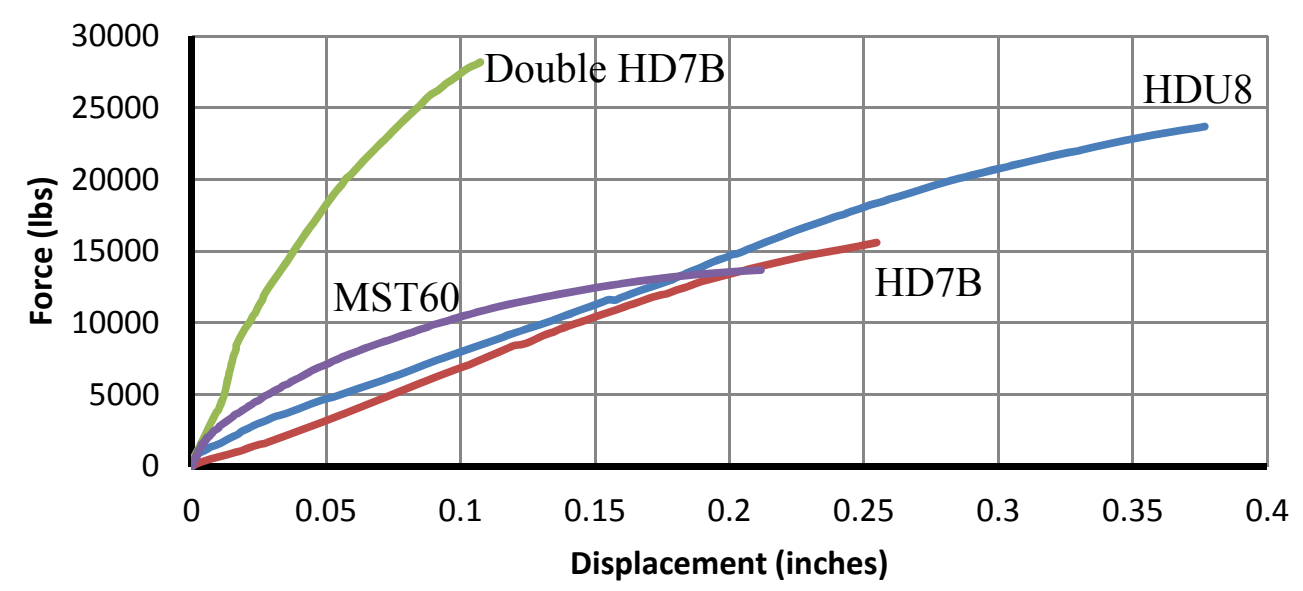

Figure 4. Stiffness Comparisons of Various Wood Cross-tie Connectors

\section{CONCLUSION}

When a large flexible diaphragm consists of a series of interconnected elements, consideration of a collective chord model provides a significant reduction in chord forces and a reduction in horizontal diaphragm deflection. Often, the design of the interconnected elements does not change under this approach because their design is dominated more by the heavy wall anchorage provisions of the building code.

While ignoring inherent collective chord behavior is conservative for diaphragm chord design, more research is needed to determine whether collective chord behavior changes the distribution of shear stresses across the diaphragm depth, potentially making today's traditional design approach for unit shear stresses unconservative.

Practitioners and researches using the diaphragm's dynamic response to more accurately determine the seismic forces acting on the building must consider the inherent stiffening effect a collective chord model creates. Additionally, the chord redundancy and low axial force levels will likely preclude inelastic chord behavior in these types of buildings.

\section{REFERENCES}

American Forest \& Paper Association (AF\&PA), (2009), Special Design Provisions for Wind and Seismic with Commentary, 2008 Edition. Washington D.C.

Applied Technology Council (ATC), (1981), Guidelines for the Design of Horizontal Wood Diaphragms, ATC-7, Berkeley, CA. p. 20. 
Graf, T. and Malley, J. O., (2004), Evaluation and Application of Concrete Tilt-up Assessment Methodologies, PEER 2004/03, Pacific Earthquake Engineering Research Center, University of California, Berkeley.

Harris, S. K. et al. (1998). "Response of Tilt-up Buildings to Seismic Demands: Case Studies from the 1994 Northridge Earthquake." Proceedings of the NEHRP Conference and Workshop on Research on the Northridge, California Earthquake of January 17, 1994. California (now Consortium of) Universities for Research in Earthquake Engineering (CUREE), Richmond, CA.

Lawson, J. W. (2007), "Thinking Outside the Box: New approaches to very large flexible diaphragms," SEAOC 2007 Convention Proceedings, Structural Engineers Association of California, Squaw Valley, CA.

Rogers, C. and Tremblay, R. (2003). "Inelastic Seismic Response of Frame Fasteners for Steel Roof Deck Diaphragms." J. Struct. Eng., ASCE, 129(12), p. 1647.

Simpson Strong-Tie (2013), Wood Construction Connectors 2013-2014, Pleasanton, CA. pp. $46-50$

Steel Deck Institute (SDI), (2004). Diaphragm Design Manual, Third Edition, Fox River Grove, IL.

Structural Engineers Association of California (SEAOC), (2008), "Tilt-Up Buildings," The SEAOC Blue Book: Seismic Design Recommendations, SEAOC Seismology Committee, Sacramento, CA. http://www.seaoc.org/bluebook (January 3, 2013).

Structural Engineers Association of California (SEAOC), (2012). "Design Example 5: Tilt-up Building," 2009 IBC Structural/Seismic Design Manual - Vol. 2, Sacramento, CA.

Structural Engineers Association of Northern California (SEAONC), (2001). Guidelines for Seismic Evaluation and Rehabilitation of Tilt-up Buildings and Other Rigid Wall / Flexible Diaphragm Structures. San Francisco, CA.

Tissell, J. R., and Elliott, J. R. (2000). Plywood Diaphragms - Report 138, APA The Engineered Wood Association, Tacoma, WA.

USP, (2011). USP Professional Design Manual and Product Catalog $-56^{\text {th }}$ Ed., United Steel Products Co., Burnsville, MN. pp. 36-40.

Yarber, C. N., (2012). Experimental Determination of the Stiffness and Strength of Continuity Tie Connections in Large Wood Roof Diaphragms, and Impact on the Collective Chord Model, Thesis (M.S.), California Polytechnic State University, San Luis Obispo. 